\title{
NEW ZEALAND'S MIGRANT ASIAN NURSES: RECENT TRENDS, FUTURE PLANS
}

\author{
Léonie Walker And Jill Clendon \\ New Zealand Nurses Organisation \\ PO Box 2128, Wellington 6140
}

\begin{abstract}
Nurses make up the largest component of the health workforce. New Zealand currently has around 47 thousand registered and enrolled nurses, of whom, about a quarter originally trained overseas. For the last six consecutive years, new overseas registrations have approximately equalled or exceeded the number of New Zealand trained new registrations, with 19 per cent of all new registrations in 2013 coming from India, China and South East Asia. The average age of nurses in New Zealand is now 48, and attracting and retaining younger nurses (both New Zealand and overseas educated) will be essential if the predicted increase in demand for nurses due to an ageing population coincides with peak retirement of older nurses in approximately fifteen years. Using multiple data sources, this paper summarises these changes and reports the findings related to career plans reported by Asian respondents from a recent New Zealand Nurses Organisation (NZNO) survey (the New 2 NZNO study) that have potentially serious implications for the sustainability of New Zealand's nursing workforce. Foremost among these is that modelling assumptions currently proposed to ensure an adequate nursing workforce are likely to severely overestimate the effectiveness of relying on internationally trained nurses to fill a predicted skill shortage long term.
\end{abstract}

\section{Background}

The New Zealand Nurses Organisation (NZNO) is the leading professional and industrial organisation of nurses in Aotearoa New Zealand, representing over 46000 nurses, midwives, students, kaimahi hauora and health workers on a range of employment-related and professional issues. NZNO has a commitment to the Treaty of Waitangi (te Tiriti o Waitangi) as the founding document of Aotearoa New Zealand and articulates their partnership with te Tiriti through Te Runanga o Aotearoa. As part of NZNO's commitment to the development of nurses and nursing in New Zealand, this research has been undertaken in order to identify and report specifically the career intentions of younger Asian nurses in New Zealand. 
As signalled in the report by Berl for the Nursing Council (2013a) "Future Nursing Workforce Supply Projections 2010 - 2035", the demand for health care (and nursing care in particular) driven by population factors such as ageing and increased life expectancy among the general population is expected to increase the requirement for nurses. As the nursing workforce is also ageing (the average age is now 48), it is predicted that over 50 per cent of our present workforce will retire by 2035 . Therefore the supply of nurses must replace the increasing numbers of nurses who are retiring and meet the extra demand for nurses as a result of population changes. Concern has been raised within the health sector about the future size, skills and attributes of the nursing workforce. These concerns are significant as nurses are the largest occupational group within the health sector and play a key role in the provision of health care.

Out of 50,791 registered nurses there were 11,415 practising Internationally Qualified Nurses (IQN) on the register at 31 March 2013. This represents 24 per cent of the overall practising nurse workforce. The age composition of the nursing workforce also differs considerably by ethnicity, with IQN increasingly over represented in the youngest quadrant of the age range (Nursing Council of New Zealand, 2013b).

One of four key strategies put forward to address the dual forces of increased demand and increased retirement is to increase still further the supply of IQN. The nursing workforce in New Zealand already has one of the highest proportions of migrant nurses (Zurn \& Dumont, 2008), and one of the most mobile workforces of all the OECD countries, with up to a quarter initially qualifying overseas, and around a quarter of the total registered nursing workforce moving either into or out of New Zealand annually (Nursing Council of New Zealand, 2013b). The Nursing Council is responsible for the registration and regulation of all registered nurses, and as registration is mandatory under the Health Practitioners Competence Assurance (HPCA) act, their workforce statistics are the most comprehensive datasets for registered nurses in New Zealand.

Nearly half of all nurses added to the register annually for each of the last five years initially qualified overseas (for example, 1278 IQN were added compared to 1639 New Zealand educated new registrants in 2013). Being New Zealand educated does not equate with being New Zealand born: the proportion of international nursing students has also grown, from 1 per cent (of total enrolments) in 1995 to 19 per cent in 2012. At some education providers, up to 30 per cent of all nursing students are Asian (particularly Indian and Chinese nurses who often have to completely re-train here due to prior qualifications not being recognised by Nursing Council). 
Much is known about the numbers of overseas trained nurses joining the New Zealand Register, (Nursing Council NZ, 2013b), and about the changing patterns of the source countries for nurses in New Zealand (Badkar, Callister, \& Didham, 2008). Badkar et al also highlighted the differences that country of origin make to the accompanying family structure of migrants - a strong predictor of long-term settlement intentions. Countries (UK, Ireland) once primary source countries for older experienced nurses and their (settling) accompanying families, are now being replaced by younger nurses from other countries; South East Asia (particularly the Philippines), India and China.

Given the relatively recent changing scale and pattern of nurse migration into New Zealand, and the increasingly significant proportion of nurses from Asia in particular who either migrate here to work as nurses or retrain here in New Zealand, it is becoming ever more important to understand their career intentions, and the impact that such intentions, if followed through, would have on the New Zealand nursing workforce supply in future.

\section{Method}

This paper is a retrospective subset analysis of data representing the IQN Asian respondents from the 2012 New to NZNO (N2N) survey, which was targeted at those who had joined NZNO in the previous five years. Answers from all Asian respondents to questions relating to registration with the Nursing Council, country of first qualification as a nurse, and career intentions were analysed. The full methodology, response rates and other findings from the studies are available on line (Walker, \& Clendon, 2012). Numerical data were analysed descriptively and represented graphically using Excel 2007. Throughout, data from the Asian respondents of the N2N study are labelled N2N Asian, other N2N data: N2N Total or N2N IQN (Internationally qualified nurses) if referring to all internationally qualified respondents. Data from the New Zealand Nursing Council are labelled $N C$ Total, NC IQN or when reporting data referring to Asian registrants only, NC Asian. 


\section{Results}

1. Source countries of total responses from N2N study, compared with the occupation code NURSE from the $2011 \mathrm{NZ}$ census

\begin{tabular}{lll}
\hline & 2011 census & N2N Total \% \\
\hline NZ & 71 & 65.9 \\
Australia & 1.7 & 1.3 \\
Fiji & 1.7 & 1.9 \\
Samoa & 0.7 & 1.7 \\
Tonga & 0.5 & 0.2 \\
UK & 11 & 14 \\
Philippines & 2.1 & 5.2 \\
China & 0.6 & 1.8 \\
India & 1.5 & 5.1 \\
South Africa & 1.7 & 2.5 \\
\hline
\end{tabular}

2. Response rate of the Asian subset of the N2N study (note, Other Asian includes S E Asian, and Philippines in the NZNO membership database)

\begin{tabular}{llll}
\hline & Invited & Responses & $\begin{array}{l}\text { \% } \\
\text { rate }\end{array}$ \\
\hline Chinese & 390 & 35 & 8.9 \\
Indian & 1185 & 70 & 6 \\
Other Asian & 1654 & 153 & 9 \\
Total & 3229 & 258 & 8 \\
\hline
\end{tabular}

This is a lower response rate from Asian respondents than the $21 \%$ response rate from the whole N2N survey.

\section{Source countries of new NZNC registrations compared to N2N IQN}

(note, most Chinese, and many Indian nurses are required to re-train in NZ to gain registration, therefore are not classed as IQN by Nursing Council).

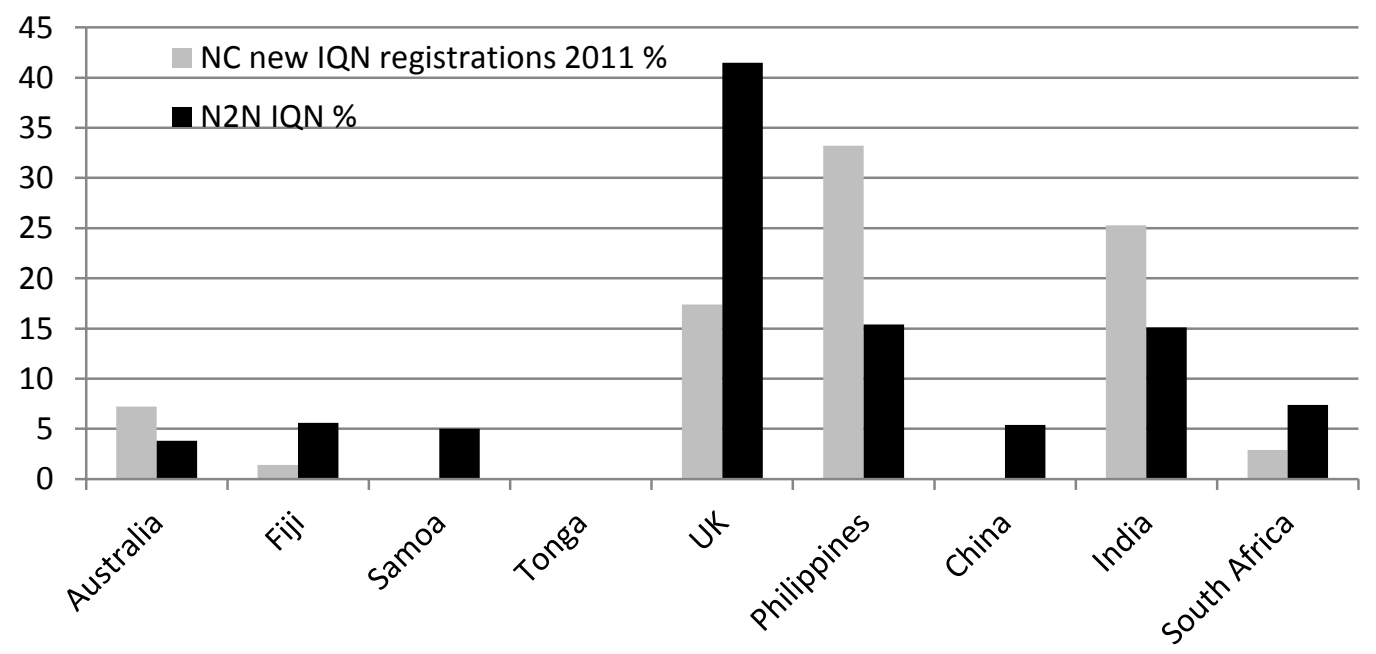

Comparisons with age and ethnicity of NC data is shown in more detail below 
4. Numbers and ages of Asian respondents compared Nursing Council

\begin{tabular}{lllllll}
\hline Age & N2N Asian (n) & NC Asian (n) & $\begin{array}{l}\text { \% } \\
\text { Asian }\end{array}$ & N2N & \% NC Asian & \% NC total \\
\hline $\mathbf{2 1 - 2 5}$ & 51 & 256 & 15 & 3.5 & 3.2 \\
$\mathbf{2 6 - 3 0}$ & 102 & 2002 & 36 & 27 & 8.9 \\
$\mathbf{3 1 - 3 5}$ & 29 & 1398 & 15 & 18.9 & 8.5 \\
$\mathbf{3 6 - 4 0}$ & 33 & 988 & 12.4 & 13.4 & 9.2 \\
$\mathbf{4 1 - 5 0}$ & 34 & 1515 & 17.25 & 20.5 & 26 \\
$\mathbf{5 1 - 6 0}$ & 9 & 838 & 4 & 11.3 & 29.3 \\
over 60 & 0 & 265 & 0.1 & 3.6 & 14.5 \\
Total & 258 & 7385 & & & \\
\hline
\end{tabular}

Source, Nursing Council New Zealand 2013 Workforce Statistics

Shown graphically, this emphasises the younger age profile of recent Asian joiners of NZNO. This may also show the older settled (and indigenous) ethnic nurses on the NC register rather than those new to nursing in New Zealand and new to NZNO.

5. Numbers and ages of Asian respondents compared to Nursing Council

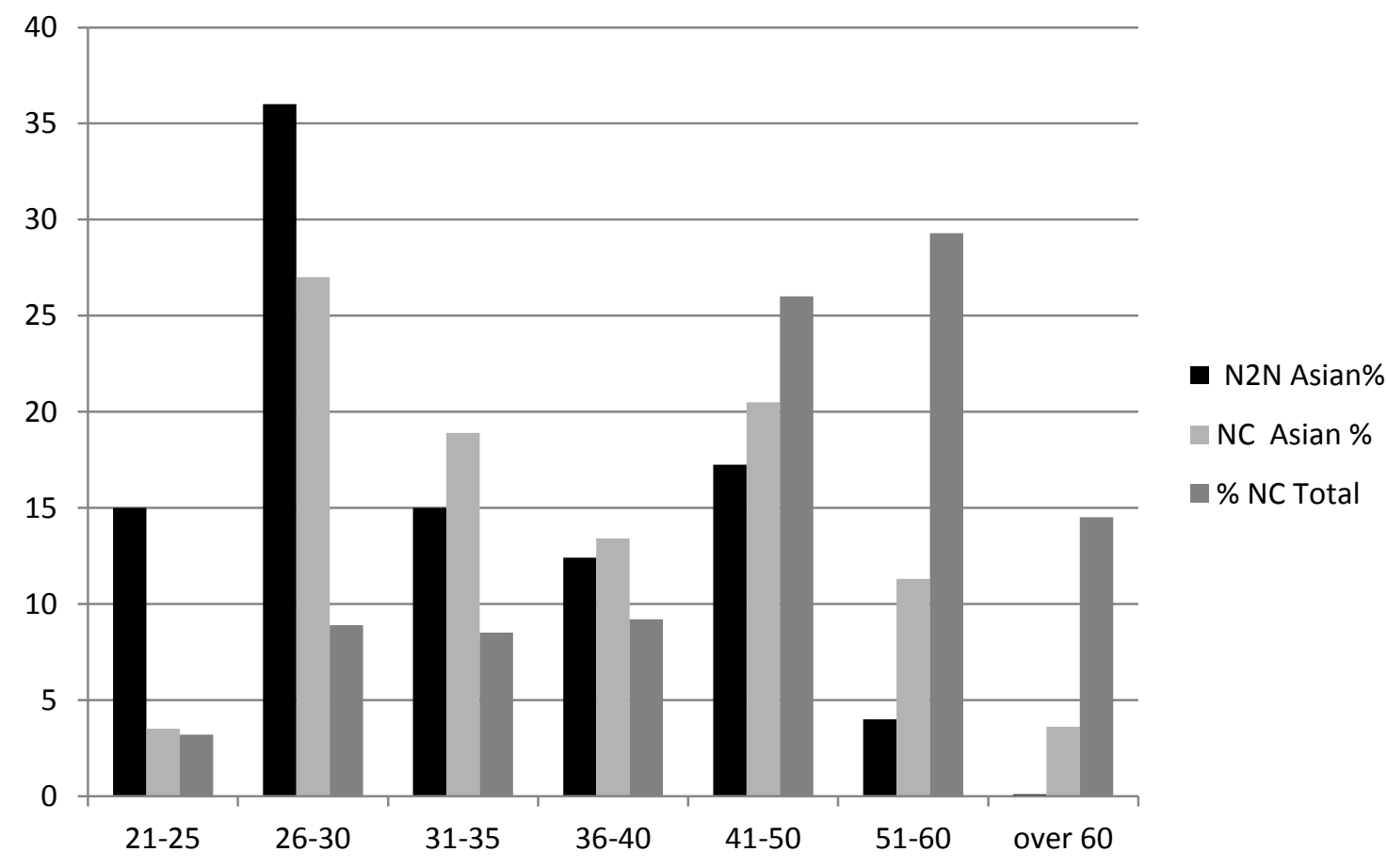




\section{Practice area of N2N Asian respondents, percentage, compared to total Nursing Council registrations}

(Other/not stated includes both chosen "other" and all NC codes not included in the NZNO data set)

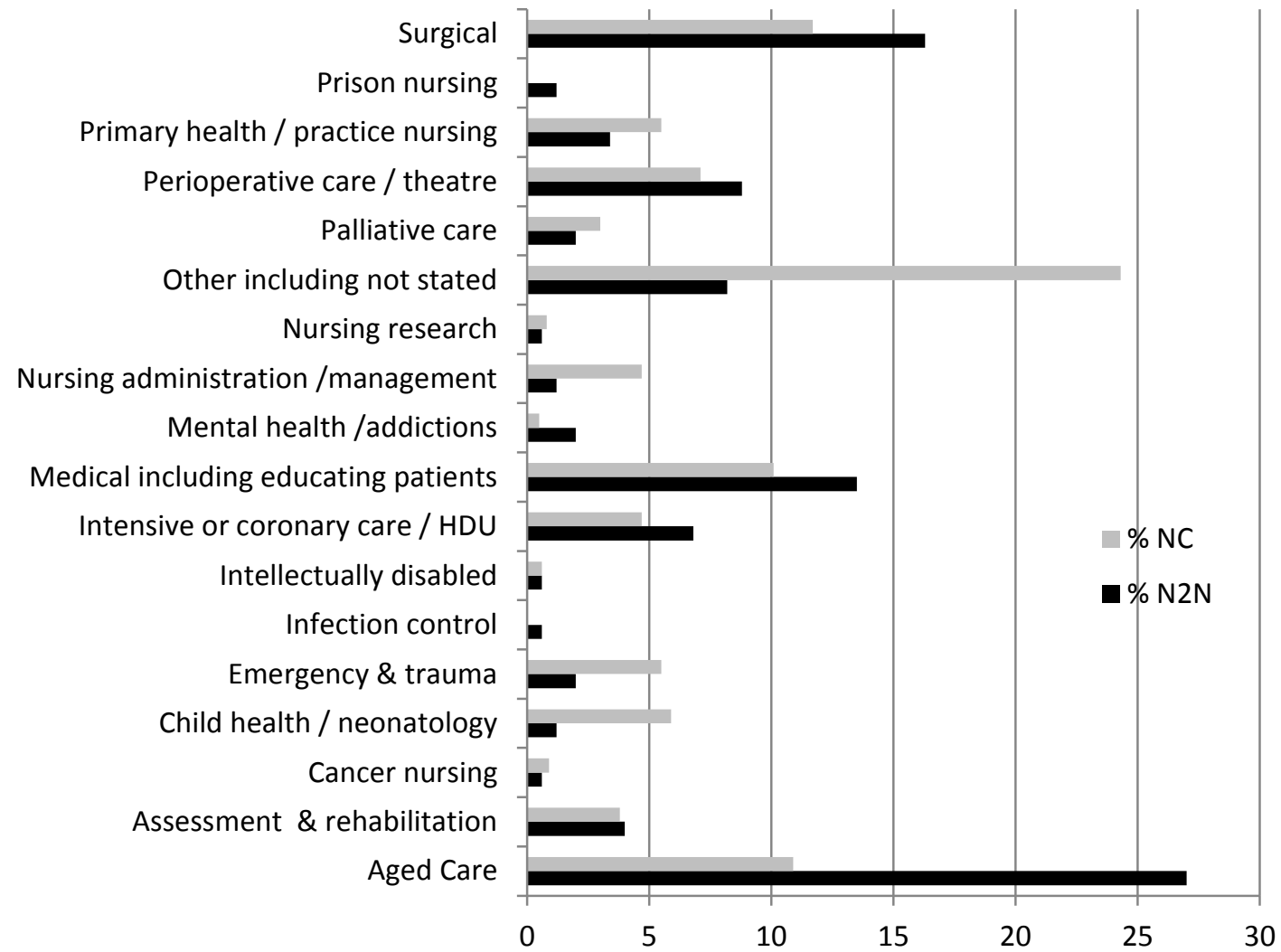

This graph confirms that recent Asian NZNO members disproportionately work in the aged care sector, as does the graph below.

\section{Employers of N2N Asian respondents, percentage, compared to total Nursing Council} registrations

(Other not stated includes chosen "other" and all the NC codes not included in the NZNO data set)

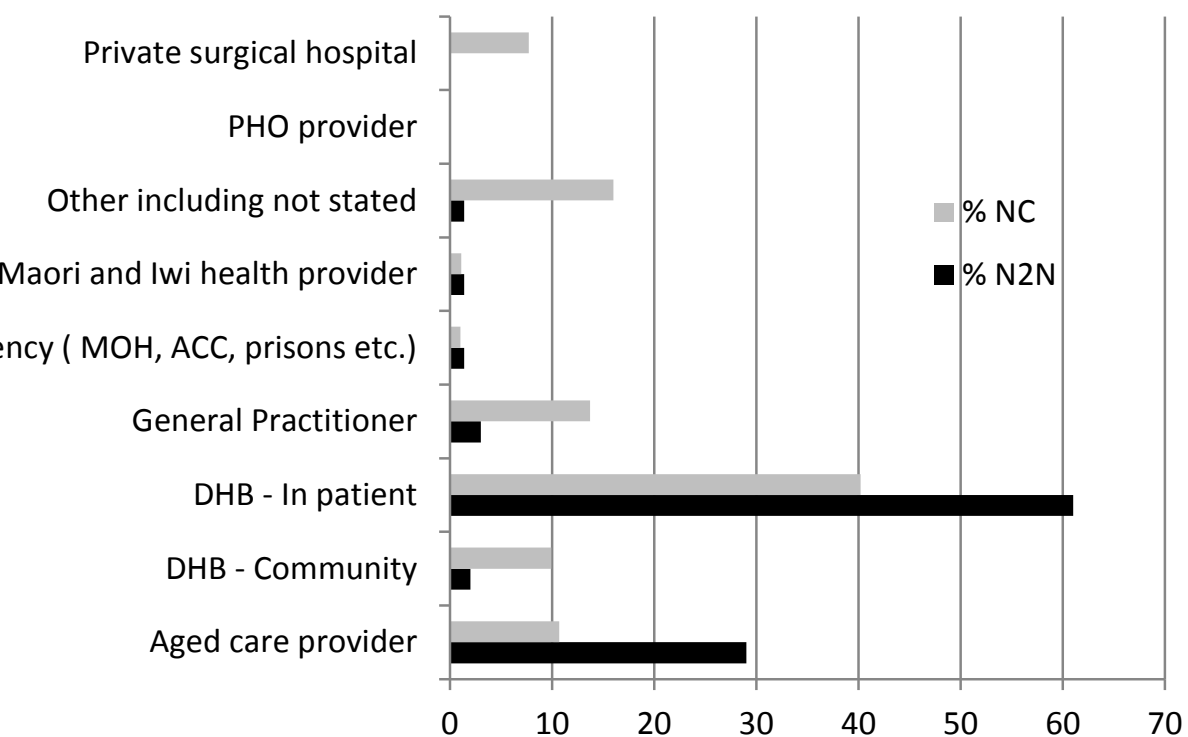


8. Geographical distribution of Asian N2N respondents Comparison with total Nursing Council registrations (Other not stated includes chosen "other" and all the NC codes not included in the NZNO data set)

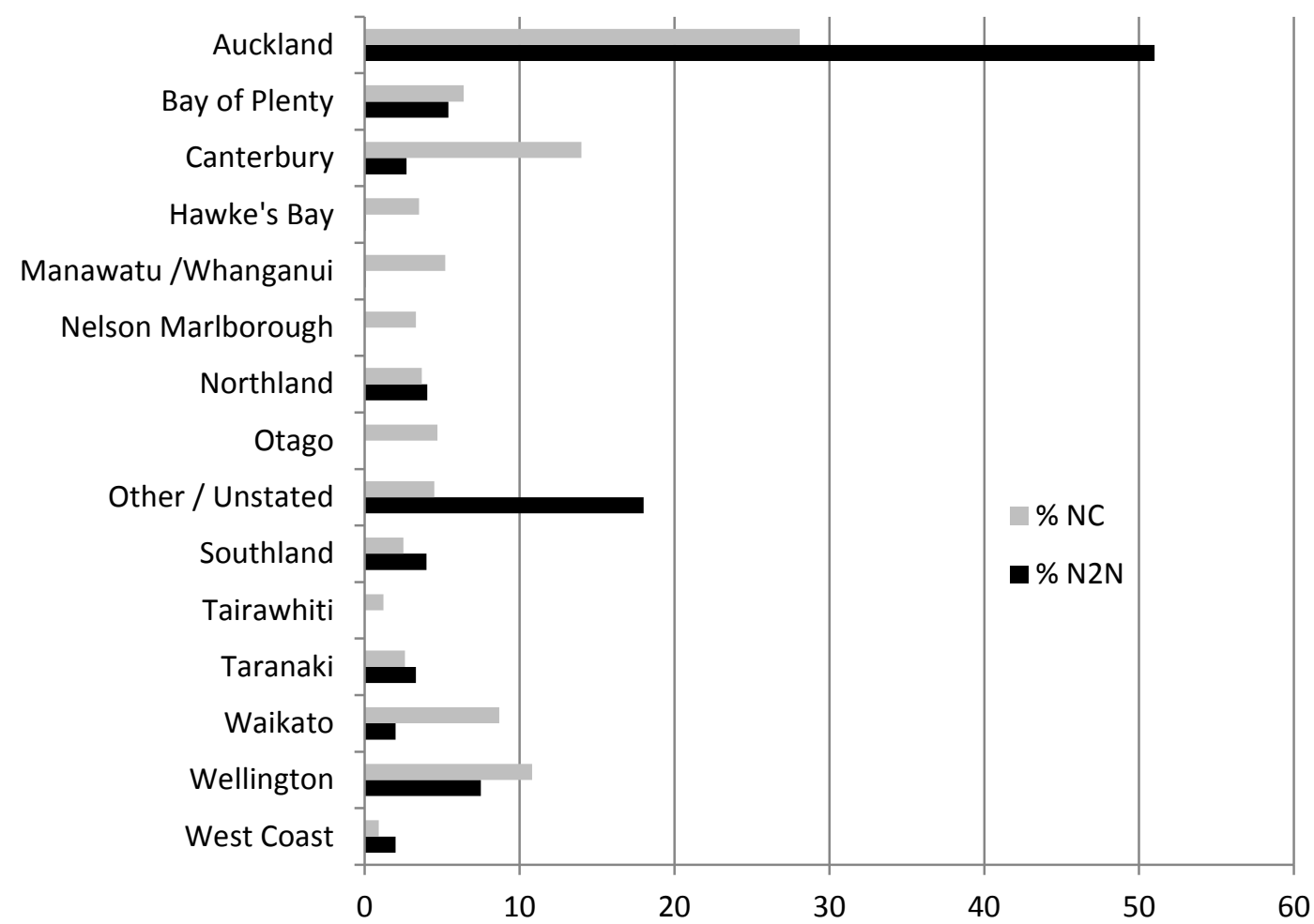

As with migration figures generally, Auckland is the destination city for a large proportion of Asian nurses.

9. Plans to stay and nurse in New Zealand by ethnicity, N2N Asian subset (note," not sure" category also includes no answer)

$(\%)$

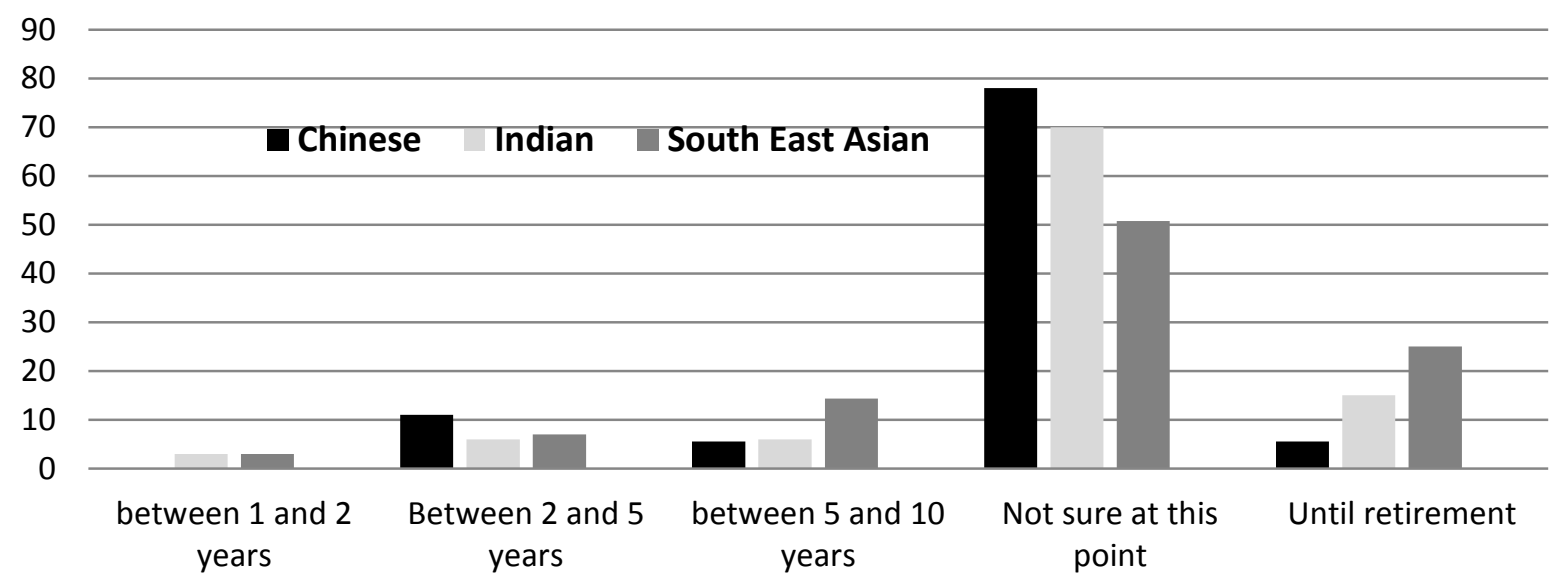

A large proportion was not sure of their longer term plans. Forty six per cent reported actively job hunting. Of these, a third (or fifteen per cent of all Asian N2N respondents), were considering nursing outside New Zealand. (Australia, a destination country for a majority of nurses leaving the NZ register, currently lists many nurse roles on its skill shortage list, which along with the 
Trans-Tasman Mutual Recognition scheme enables any NZ trained nurse to work in Australia.) When asked why they were considering a change, the most common reasons given were to seek work with better pay, better terms and conditions and personal or family reasons. Additional comments from Asian respondents (twenty nine per cent made specific comments, the overwhelming majority negative), regarding their experience of nursing in New Zealand highlighted several themes. The major themes and exemplar quotes are shown below:

\section{Discrimination}

Favouring western names for selecting employees; also avoiding the person with difficult long names. Preferring white skin colour to dark skin colour,

As trained in India and haven't had NZ experience many applications from many of us are being rejected by a lot of employers in $N Z$.

Sometimes, the patients or parents of patients say things like "Thank God I can see white nurses around...I always see Asians everywhere"

\section{Management issues}

Shift schedules; the NZ nurses pick the schedules of their choice where foreign nurses are left with the unwanted rosters like weekends, and grave schedules. Personally I have not been given days off on a weekend since I started working here.

bullying and discrimination against migrant nurses is commonplace.

\section{Difficulties with accent}

\section{Criticising different accents}

Being an overseas trained nurse proved to be difficult for me especially the language barrier. I was trained to have an American English accent and some New Zealanders find it difficult to understand my accent. I was more than once asked how I obtained registration

\section{Pay not related to experience}

Also some employers do not consider the overseas experience we have had when deciding salary and we are being paid as new graduates

I got a job offer at a lower salary scale for my experience because I'm trained overseas

\section{Discussion}

There are differences between the Asian subset of nurses in New Zealand that responded to the N2N survey and the total Nursing Council Asian nurse registration data. The main differences include a tendency for newer migrants, especially Asian ones, to settle in the Auckland region. This is true of migrants in general (Statistics New Zealand, 2013). The aged care employment sector makes up a disproportionately large proportion of Asian newer members of NZNO. The smaller percentage of Asian IQN responding in the N2N survey compared to the proportions 
reported by Nursing Council may also reflect that nurses from the Philippines (South East Asia, or SEA) in particular work in aged care (for their first jobs at least) and that aged care is more poorly unionised than the DHB sector (David Waite, personal communication, August 2014). A higher proportion of UK nurses than migrants from non-English speaking countries move to DHB positions. The N2N sample also shows a higher proportion of respondents from the UK (graph 3) than reflects the Nursing Council data. The vast majority of Nurses in the UK belong to the Royal College of Nurses (RCN), and so UK migrants are more familiar with the Union and Professional Organisation structure of NZNO than nurses from non-unionised countries like the Philippines. It should also be remembered that very many SEA nurses struggle to gain registration with the Nursing Council, and work as care givers in aged care. The N2N sample was limited to registered nurses, therefore underestimates SEA nurses in aged care. The negative experiences of migrant nurses (especially Asian migrants) have been previously reported by Walker, (2012) Clendon and Walker, (2012), Walker and Clendon (2012), Walker and Clendon, (2013) and Clendon and Walker, (2013), reflecting these issues in three different surveys undertaken over three years. Progress has been made in some quarters, with an excellent set of resources for employers and employees in aged care produced by the Immigration Department (Department of Immigration NZ, 2014). Guidance was also produced in 2013 by NZNO (New Zealand Nurses Organisation, 2013).

Migrants in many sectors find their previous skills and qualifications are not recognised in New Zealand, and one study calculated that on average, migrants lose fifteen years in terms of career progression and salary compared to age / qualification matched New Zealanders. While this may be a fact of life, and have some legitimate basis, the mismatch between expectations and experience is what often leads to dissatisfaction (Tausi, 2013).

Nursing codes and values stress the importance of cultural safety, and of non-discriminatory practice. An increasingly diverse patient population - particularly in Auckland - would indicate that ensuring the nursing workforce reflects patient and community ethnic profiles is also desirable. Current workforce statistics indicate a mismatch between patient and nurse ethnicities in many geographical areas. Māori nurses, and nurses from the Pacific Islands are also frequently under represented, and there is evidence that New Zealand born ethnically Indian and Chinese are under-represented in nursing school rolls. This situation will only continue while ethnic Indian and Chinese migrants experience discrimination and perceptions of stigma in the workplace compared to other professions (de Bres, 2013), and while other career options attract able Asian New Zealanders. 
From a workforce planning perspective, one scenario proposed by the Nursing Council (2013a) is to increase the proportion of IQN (especially younger nurses) to replace the ageing and retiring current workforce. The findings from this research, while small in scale, would if extended to the Asian migrant workforce more widely, indicate that this route is likely to result in a revolving door rather than a settled workforce to a much higher degree than previously thought.

Another scenario, that of training more young nurses in New Zealand, will also struggle to achieve the intended outcome if the issues faced by new graduates in gaining employment, and by young nurses in the workplace, and of disparity in earning potential and quality of working environment compared to other similarly educated and responsible professionals are not addressed (Clendon \& Walker, 2013).

While the numbers of respondents are low, and the findings relate to self-reported issues, the stability of the results over time, and the consistency of the demographics related to age, ethnicity, field and geographical dispersal between surveys and datasets mean that the implications for longer term nursing workforce planning need to be examined further and necessary interventions implemented (New Zealand Nurses Organisation, 2013).

Repeatedly importing, training, hiring and orientating new Asian migrant nurses, only for them to leave within two to five years is wasteful. It is detrimental to migrant nurses and unsettling for the nursing workforce generally - diverting valuable resources orientating and mentoring new nurses. Additionally, fatigue and cynicism about the value of orientating new nurses "when they will only leave" adds to what are becoming potentially serious multicultural tensions in the workplace. Ensuring a safe, welcoming, fair, and professionally rewarding working environment is vital to assisting with longer term retention.

\section{Conclusion}

This paper reports evidence that migrating Asian nurses are unlikely to remain in the New Zealand nursing workforce for more than two to five years - preferring instead to migrate onto Australia for better terms and conditions, or back to their home countries with enhanced job prospects. If the proposed policy driver of increased migration is to be relied upon to ensure workforce adequacy then the issues that also contribute to dissatisfaction with employment as nurses in New Zealand (where at all possible) must be urgently addressed. 


\section{References}

Badkar, J., Callister, P., \& Didham, R. (2008) The origin, family structure and labour supply of overseas born nurses, $13^{\text {th }}$ Labour Employment and Work Labour, Employment and Work, http://ojs.victoria.ac.nz/LEW/article/view/1657 retrieved 20.11.2014

Clendon, J., \& Walker, L. (2012) 'Being young': younger nurses' experiences in the workplace. International Nursing Review, 59(4), 555-61.

Clendon, J., \& Walker, L. (2013) Young nurses in Aotearoa New Zealand Research Advisory Paper; Highlights of the NZNO Younger Nurse Study, Wellington: New Zealand Nurses Organisation

Department of Immigration NZ (2014), Aged Care: Employers Guide and Employees guide http://www.immigration.govt.nz/NR retrieved 18.07.2014

de Bres, J., (2010) Discrimination Against Asians Still A Key Issue In New Zealand - Updated http://emigratetonewzealand.blogspot.co.nz

New Zealand Nurses Organisation (2013) Here to stay: guidance for the safe and effective integration of Internationally qualified nurses (IQN) into the Aotearoa New Zealand workforce, NZNO Wellington.

Nursing Council (2013a) The Future Nursing Workforce Supply Projections 2010 - 2035 (Berl) http://www.nursingcouncil.org.nz/Publications/Reports

Nursing Council New Zealand (2013b) Workforce statistics http://www.nursingcouncil.org.nz/Publications/Reports

Statistics New Zealand (2013) Migration and Age. Available: http://www.stats.govt.nz/browse for stats/population/Migration/internalmigration/migration-and-age.aspx

Tausi, M. (2013) Skills \& International Migration in New Zealand, Labour Employment and Work http://ojs.victoria.ac.nz/LEW/article/view/1980 retrieved 20.11.2014

Walker, L. (2008) A mixed picture: the experiences of overseas trained nurses in New Zealand, Labour Employment and Work http://ojs.victoria.ac.nz/LEW/article/view/1658 retrieved 20.11.2014

Walker, L. \& Clendon, J. (2012) N2N: New to NZNO Membership Project Part two. A multicultural nursing workforce: views of overseas and New Zealand trained nurses. Wellington: New Zealand Nurses Organisation.

Walker, L., \& Clendon, J. (2013). NZNO employment survey: our nursing workforce: 'for close observation'. Wellington: New Zealand Nurses Organisation.

Zurn, P. and Dumont, J-C. (2008). Health workforce and international migration: can New Zealand compete? OECD Working Papers 33. Paris: OECD and WHO. 